\title{
Influência do eugenol na microdureza da resina composta utilizando sistemas adesivos atuais
}

\section{Influence of eugenol on the microhardness of composite resin using current bonding systems}

\author{
André Rubio de SOUZA* \\ Fernanda Bernardo de MELLO* \\ Míriam Lacalle TURBINO** \\ Michel Nicolau YOUSSEF***
}

\begin{abstract}
SOUZA, A. R.; MELLO, F. B.; TURBINO, M. L.; YOUSSEF, M. N. Influência do eugenol na microdureza da resina composta utilizando sistemas adesivos atuais. Pesqui Odontol Bras, v. 14, n. 3, p. 237-242, jul./set. 2000.

O objetivo deste trabalho foi avaliar, in vitro, se a utilização do cimento de óxido de zinco e eugenol exerce influência na microdureza da restauração de resina composta (Z100) realizada com dois sistemas adesivos (Scotchbond Multi-Purpose Plus ${ }^{\circledR}$ - sistema que remove o "smear layer", e o Clearfil Liner Bond $2^{\mathbb{R}}$ - adesivo que promove o tratamento do "smear layer", sem removê-lo totalmente). Para isto, foram utilizados 40 molares humanos hígidos que foram divididos igualmente em 4 grupos. Para cada adesivo havia um grupo controle (sem óxido de zinco e eugenol) e outro onde foram realizadas e removidas as restaurações provisórias com cimento de óxido de zinco e eugenol. Após sete dias de armazenamento em estufa a $37^{\circ} \mathrm{C}$, os dentes foram cortados e mediu-se a microdureza da resina composta na região a $0,3 \mathrm{~mm}$ da interface dente-restauração em um microdurômetro SHIMADZU HMV 2000, com ponta penetradora Knoop de 50 gramas por 45 segundos. Os resultados obtidos foram analisados estatisticamente pela ANOVA ( $\alpha=1 \%)$, e verificou-se não haver diferença estatisticamente significante na microdureza da resina composta entre os grupos estudados.
\end{abstract}

UNITERMOS: Adesivos dentinários; Cimento de óxido de zinco e eugenol; Resinas compostas.

\section{INTRODUÇÃO}

Em 1955, BUONOCORE ${ }^{1}$ introduziu a técnica de condicionamento ácido de esmalte nos procedimentos restauradores para melhorar a adesividade das resinas acrílicas. Com o surgimento das resinas compostas que, utilizadas juntamente com os adesivos, apresentavam ótima retenção às paredes tanto de esmalte quanto de dentina promoveu-se uma grande mudança nos conceitos de restauração, uma vez que possibilitava preparos mais conservadores evitando desgaste de dente sadio.

Atualmente, a proposta da Odontologia Restauradora está baseada em dois princípios fundamentais: vedamento canalicular e vedamento marginal. Isto é possivel em função do condicionamento ácido total, ou seja, da dentina e do esmalte, associado ao uso dos sistemas adesivos. A remoção do esfregaço elimina o substrato orgânico, diminui o número de bactérias na microfissura entre o dente e a restauração, reduzindo assim a possibilidade de problemas pulpares ${ }^{3,4}$.

A técnica adesiva foi padronizada pela maioria dos fabricantes na seguinte seqüência: condicionamento ácido total (geralmente ácido ortofosfórico a $37 \%$ ), uso do "primer" (preparador de dentina) e finalmente do adesivo. Um exemplo comercial é o sistema adesivo Scotchbond Multi-Purpose Plus ${ }^{\circledR}$ que, com o condicionamento ácido total, remove toda camada de esfregaço e dissolve o componente inorgânico da dentina inter- e peritubular, resultando na exposição da porção orgânica da dentina, constituída basicamente por fibras colágenas da porção intertubular ${ }^{14}$.

O "primer", utilizado após a lavagem do ácido, condiciona as fibras colágenas da dentina, as quais ficam sem suporte, e possibilita a impregnação dessa dentina pelo adesivo ${ }^{12}$. Este penetra no interior do túbulo dentinário envolvendo as fibras colágenas e ao ser polimerizado apresenta-se na

\footnotetext{
* Estagiários Didáticos da Disciplina de Dentística Operatória; **Professora Doutora; ***Professor Associado - Departamento de Dentística da FOUSP.
} 
SOUZA, A. R.; MELLO, F. B.; TURBINO, M. L.; YOUSSEF, M. N. Influência do eugenol na microdureza da resina composta utilizando sistemas adesivos atuais. Pesqui Odontol Bras, v. 14, n. 3, p. 237-242, jul./set. 2000.

forma de prolongamentos de resina. Isto resulta na formação de uma zona de transição descrita pela primeira vez por NAKABAYASHI et al. ${ }^{13}$ (1982) como a camada híbrida: "Entrelaçamento definitivo entre o adesivo e as fibras colágenas da dentina. A dentina fica reforçada pelo adesivo, constituindo uma barreira à penetração de bactérias".

Atualmente, alguns fabricantes apresentam sistemas adesivos do tipo simplificados, que concentram em um só frasco o "primer" e o adesivo. Outros, o ácido e o "primer" como por exemplo, o Clearfil Liner Bond $2^{17,19}$.

Na maioria dos procedimentos restauradores, a restauração é completada na mesma sessão, entretanto, algumas vezes é necessária a colocação de restaurações provisórias ${ }^{9}$. Dentre os materiais restauradores para este fim, destaca-se o cimento de óxido de zinco e eugenol que tem como características favoráveis ao seu uso a boa adaptação marginal por curto período de tempo, biocompatibilidade e propriedades anódinas. O mecanismo de reação de presa desse cimento não é muito bem conhecido, mas sabe-se que da combinação do óxido de zinco (pó) com o eugenol (presente no líquido) forma-se o eugenolato de zinco acrescido de partículas de óxido de zinco que não reagiram, além de eugenol livre em pequena quantidade ${ }^{18}$. Esse eugenol remanescente na cavidade pode, segundo GANSS $^{5}$ (1998), LÓSSIO ${ }^{8}$ (1987) e PAIVA ${ }^{15}$ (1993), interferir na polimerização das resinas.

O objetivo deste trabalho foi verificar, simulando-se situações clínicas, se com a utilização dos sistemas adesivos, que tratam ou removem o esfregaço dentinário, ocorre a remoção do eugenol que possa estar no interior dos túbulos dentinários, ou se os possiveis resíduos que restaram após o condicionamento influenciam a polimerização da resi-

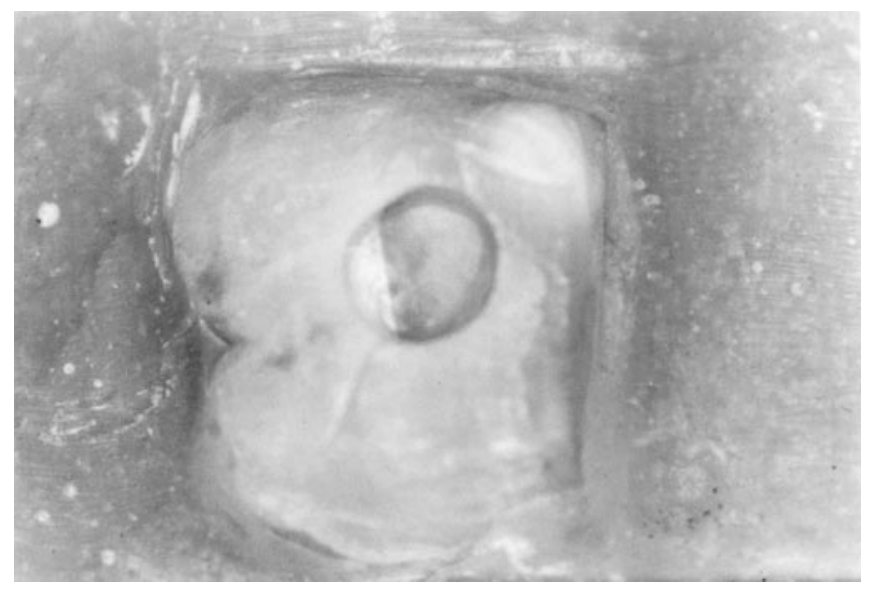

FIGURA 1 - Preparo. na composta. Tal fato foi averiguado por meio da medida da microdureza da resina com penetrador Knoop de um microdurômetro.

\section{MATERIAL E MÉTODOS}

Selecionaram-se 40 dentes humanos entre o grupo dos molares, hígidos, extraídos por razões diversas. Os dentes foram acondicionados por pelo menos 72 horas em potes de vidro contendo soro fisiológico a temperatura ambiente.

As raizes foram removidas com o auxilio de discos de "carborundum" acoplados ao micromotor. As coroas clínicas foram incluídas em fôrmas de gelo (cada forma medindo $4,5 \mathrm{~cm}$ de comprimento $x 3,0 \mathrm{~cm}$ de largura $\times 3,5 \mathrm{~cm}$ de altura). Inicialmente, foram feitas linhas de orientação com caneta de retroprojetor que delimitavam até que altura da fôrma a resina acrílica ativada quimicamente (RAAQ) deveria ser colocada, precedida do isolante vaselina. Em seguida, as coroas foram colocadas no centro das formas, com o sentido mésio-distal paralelo ao maior comprimento destas. Após a polimerização da RAAQ e remoção das cubas de gelo, obteve-se o corpo-de-prova final.

Em todas as coroas, foram realizados preparos classe $\mathrm{V}$ com o auxílio de pontas diamantadas $n^{\circ}$ 2.094. Os preparos foram realizados na face vestibular dos dentes (Figura 1) e apresentavam 3,0 $\mathrm{mm}$ de profundidade conseguida com demarcação realizada na parte ativa da ponta, de tal forma que a profundidade dos preparos foi sempre a mesma. O formato circular das cavidades apresentava 3,0 $\mathrm{mm}$ de diâmetro conferido com o auxílio de um paquímetro.

Após a realização das cavidades, os corpos-de-prova foram lavados com tergentol, água e

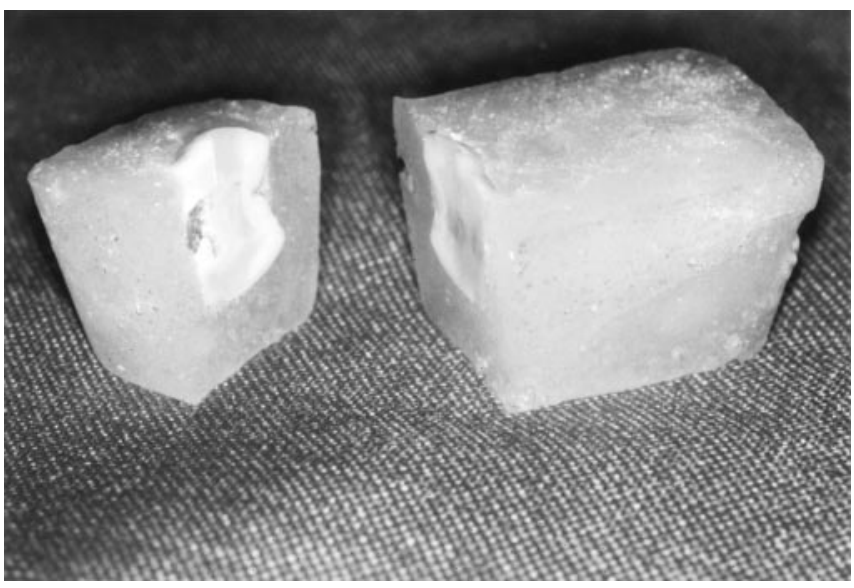

FIGURA 2 - Corpos seccionados. 
SOUZA, A. R.; MELLO, F. B.; TURBINO, M. L.; YOUSSEF, M. N. Influência do eugenol na microdureza da resina composta utilizando sistemas adesivos atuais. Pesqui Odontol Bras, v. 14, n. 3, p. 237-242, jul./set. 2000.

secos por meio de bolinhas de algodão. Eles foram divididos em 4 grupos com 10 espécimes, servindo como controles os dois primeiros grupos.

O grupo I recebeu restaurações com resina composta Z100 (cor A2) após tratamento com o sistema adesivo Scotchbond Multi-Purpose Plus. A resina composta foi colocada em pequenas porções na cavidade (técnica incremental - Davidson e Dee Gee, 1984) e fotopolimerizada por 40 segundos para cada passo, com um aparelho Translux ajustado em $400 \mathrm{~mW} / \mathrm{cm}^{2}$. Dez corpos-de-prova foram restaurados imediatamente com o compósito (grupo controle). Os outros 10 receberam restaurações com cimento de óxido de zinco e eugenol antes de serem restaurados definitivamente (grupo experimental).

O grupo II teve o mesmo procedimento utilizado no grupo I com a mudança do sistema adesivo que neste grupo foi o Clearfil Liner Bond 2. Em todos os grupos, as restaurações permaneceram 8 dias em estufa a $37^{\circ} \mathrm{C}$. Após esse tempo, nos dois grupos experimentais o cimento de óxido de zinco e eugenol foi removido com a mesma ponta que foi utilizada para realização dos preparos, mas acoplada a um adaptador para contra-ângulo, com o objetivo de diminuir a velocidade facilitando o controle da remoção. Após a remoção do óxido de zinco, as cavidades foram restauradas com resina composta.

Os grupos, antes de serem restaurados com resina, receberam tratamento, conforme especificação do fabricante, com os sistemas adesivos Scotchbond Multi-Purpose Plus - grupo I e Clearfil Liner Bond 2 - grupo II. No grupo II, foi misturada uma gota do "primer" A com o B; a mistura foi aplicada na cavidade com pincéis $\mathrm{n}^{\circ} 1$ (em esmalte e dentina) e após 30 segundos receberam leves jatos de ar a distância por 5 segundos; em seguida, o adesivo foi levado à cavidade também com pincel $\mathrm{n}^{\circ} 1$ abrangendo esmalte e dentina e fotopolimerizado por 20 segundos. Nos grupos em que foi utilizado o sistema Scotchbond, fez-se ataque ácido no esmalte e dentina por 15 segundos, lavagem por 15 segundos com água e secagem com jato de ar a distância por 5 segundos deixando a superficie ligeiramente úmida a fim de melhorar a adesão; aplicou-se o "primer" e secou-se com jatos de ar a distância por 5 segundos; em seguida, foi feita aplicação do adesivo e fotopolimerização. Em ambos os grupos, a fotopolimerização foi realizada pelo aparelho Translux com intensidade luminosa de $400 \mathrm{~mW} / \mathrm{cm}^{2}$.

Após 24 horas, os corpos-de-prova foram sec- cionados com disco de diamante do micrótomo (Figura 2), para que se pudesse medir a dureza da polimerização da resina. Para que este corte fosse realizado, os corpos foram marcados com riscos de orientação que passavam pela coroa e restauração (seguindo o sentido cérvico-oclusal) na sua porção central.

Após a realização deste corte, conseguiram-se duas metades dos corpos-de-prova, sendo que uma delas foi desprezada. As outras metades receberam polimento no aparelho Politrix-ECOMET 3 nas superficies que entraram em contato com o disco de diamante do micrótomo. Foram utilizadas 3 granulações diferentes de lixa que foram utilizadas da maior para a menor abrasividade.

As superficies polidas facilitavam a medição da microdureza Knoop da restauração na região próxima à área de união dente-restauração. Em seguida, os corpos-de-prova foram levados ao microdurômetro SHIMADZU HMV 2000 adaptados a uma Morsa Universal Ajustável (SHIMADZU). A microdureza dos compósitos foi medida com o penetrador Knoop do microdurômetro com carga de 50 gramas por 45 segundos. Esta medida foi realizada no terço central da restauração em três pontos distintos e distando 0,3 milimetros da linha de união dente-restauração. Os resultados obtidos nos dois grupos foram tabelados e comparados após análise estatística.

\section{RESULTADOS E DISCUSSÃO}

Foram feitas três medidas distintas da microdureza Knoop em cada corpo-de-prova obtendo-se 120 valores da resina composta Z100. Dessas 3 medidas, foi feita uma média para cada espécime, resultando em 40 valores, os quais foram somados e divididos pelo número de espécimes de cada grupo (10). Obtiveram-se assim médias gerais para cada um dos diferentes grupos e realizou-se a análise estatística ANOVA $(\alpha=1 \%)$. As médias finais de cada grupo, bem como as suas respectivas variâncias, estão presentes nas Tabelas 1 e 2 .

A análise estatística foi realizada por meio de um programa denominado GMC $7.1^{20}$, desenvolvido pelo Prof. Dr. Geraldo Maia Campos, da Faculdade de Odontologia de Ribeirão Preto da Universidade de São Paulo. O nível de significância utilizado nos testes foi de $1 \%$, pois pequenas variações (de 0 a 2) na microdureza Knoop da resina composta foram consideradas clinicamente insignificantes.

Estas médias gerais foram submetidas a análi- 
SOUZA, A. R.; MELLO, F. B.; TURBINO, M. L.; YOUSSEF, M. N. Influência do eugenol na microdureza da resina composta utilizando sistemas adesivos atuais. Pesqui Odontol Bras, v. 14, n. 3, p. 237-242, jul./set. 2000.

TABELA 1 - Médias.

\begin{tabular}{c|c}
\hline \hline \multicolumn{2}{c}{ Scotchbond Multi-Purpose Plus $^{\circledR}$} \\
\hline Grupo I (controle) & Grupo IV (com eugenol) $^{{ }^{\circledR}}$ \\
\hline $74,72 \pm 3,30$ & $71,48 \pm 3,20$ \\
\hline \hline
\end{tabular}

TABELA 2 - Médias.

\begin{tabular}{c|c}
\hline \hline \multicolumn{2}{c}{ Clearfil Liner Bond 2 } \\
\hline Grupo I (controle) & Grupo III (com eugenol) \\
\hline $75,04 \pm 4,43$ & $72,73 \pm 4,35$ \\
\hline \hline
\end{tabular}

se estatística pela ANOVA com nível de significância de $1 \%$. Para isto, realizou-se o teste $t$ e foram obtidos os resultados mostrados nas Tabelas 3 e 4 .

Um dos sistemas adesivos que foi utilizado neste experimento foi o Scotchbond Multi-Purpose Plus que se baseia no uso do ataque ácido total, utilizando o ácido fosfórico a 37\% para promover a remoção do esfregaço, exposição de fibras colágenas e formação de prolongamentos longos. ELIADES et al. ${ }^{4}$ (1997) avaliaram o efeito de alguns condicionadores ácidos na morfologia dentinária, na composição molecular e no colágeno. Verificaram que os que removem o esfregaço afunilam os túbulos, aumentam a rugosidade intertubular e contaminam a superficie dentinária com resíduos de agentes espessantes irreversivelmente absorvidos.

Outro sistema testado, o Clearfil Liner Bond 2 tem a seguinte composição segundo REALITY ${ }^{17}$ (1998): "primer" A, 2 metacriloxietilfenilfosfato; n-metacriloil-5 ácido-aminosalicílico (5-NMSA); n, n-dietanol-p-toluidina; d, 1-canforoquinona; álcool etílico. "Primer" B, HEMA (hidroxietilmetacrilato); dimetacrilato hidrofilico; água. Quando o "primer" A e o B são misturados, o resultado é uma solução autocondicionante que não remove o esfregaço totalmente mas modifica-o. Isto contraria NAKABAYASHI et al. ${ }^{14}$ que preconizam a remoção total do esfregaço para aumentar a adesão à dentina.

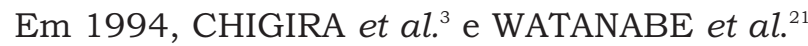
relataram as primeiras considerações sobre os adesivos autocondicionantes. O primeiro fez testes da microdureza Vickers de diferentes "primers" autocondicionantes, não constatando nenhuma diferença estatisticamente significante entre eles. Já o segundo relatou em seu experimento que, quando se utilizam "primers" autocondicionantes,
TABELA 3 - Teste $t$.

\begin{tabular}{l|c}
\hline \hline \multicolumn{2}{c}{ Scotchbond Multi-Purpose Plus } \\
\hline Valor calculado de $t$ & 2,23 \\
\hline Graus de liberdade & 18 \\
\hline Probabilidade de igualdade & $3,70 \%$ \\
\hline \multicolumn{2}{c}{ Não significante } \\
\hline \hline
\end{tabular}

TABELA 4 - Teste $t$.

\begin{tabular}{l|c}
\hline \hline \multicolumn{2}{c}{ Clearfil Liner Bond 2 } \\
\hline Valor calculado de $t$ & 1,43 \\
\hline Graus de liberdade & 18 \\
\hline Probabilidade de igualdade & $16,58 \%$ \\
\hline \multicolumn{2}{c}{ Não significante } \\
\hline \hline
\end{tabular}

a força de adesão fica similar à dos adesivos de passos múltiplos, tendo a vantagem de possuir em um só frasco a solução que serve tanto como condicionador quanto como "primer", facilitando o seu uso.

Soluções ácidas muito concentradas provocam grande descalcificação da dentina e, como conseqüência, grande profundidade de prolongamentos vazios. Esta situação, de acordo com vários autores como YOUSSEF et al. ${ }^{22}$ (1998), PRATI et al. ${ }^{16}$ (1998), não é favorável, pois os adesivos não conseguem preencher toda a extensão descalcificada. Os estudos de YOUSSEF et al. ${ }^{22}$ (1998) constataram tal situação através da microscopia eletrônica de varredura. Por outro lado, soluções ácidas mais diluídas podem provocar forças de adesão satisfatórias, como mostraram CHAN et al. ${ }^{2}$ (1997) por meio de testes de cisalhamento, que conseguiram forças de adesão por volta de $20 \mathrm{MPa}$.

O conceito de que o cimento de óxido de zinco e eugenol interfere na polimerização da resina é muito antigo na Odontologia. Sabe-se que o eugenol em contato com a resina impede a polimerização desta. Alguns autores como PAIVA; ANTONIAZZI $^{15}$ (1993) acreditam que mesmo o eugenol residual interfere na polimerização.

A dureza Knoop da resina polimerizada em contato com dentina de cavidades antes preenchidas com óxido de zinco e eugenol foi verificada neste trabalho com a utilização do aparelho microdurômetro SHIMADZU HMV 2000 que possui uma ponta penetradora. Este aparelho foi utilizado de acordo com a técnica de TURBINO ${ }^{20}$ (1997), ou seja, 
SOUZA, A. R.; MELLO, F. B.; TURBINO, M. L.; YOUSSEF, M. N. Influência do eugenol na microdureza da resina composta utilizando sistemas adesivos atuais. Pesqui Odontol Bras, v. 14, n. 3, p. 237-242, jul./set. 2000.

aplicação de carga de 50 g durante 45 segundos. Vários são os testes que podem ser realizados com o objetivo de constatar a completa polimerização das resinas. CHAN et al..$^{2}$ (1997) utilizaram teste de cisalhamento, enquanto MATSON et al. ${ }^{10}$ (1996) usaram os testes de tração e microinfiltração. Acreditamos que os resultados mais convincentes da interferência na polimerização das resinas podem ser alcançados por meio da avaliação da dureza destas resinas polimerizadas, com o que concordam os autores HARRINGTON et al. ${ }^{6}$ (1996) e MATSON et al. ${ }^{11}$ (1996).

Em nossa opinião, o condicionamento ácido da dentina, que precede o uso do sistema adesivo, pode remover eventuais resíduos de eugenol existentes na cavidade, fato que contribui para que a polimerização ocorra totalmente. Esta hipótese é também compartilhada por outros autores como MATSON et al. ${ }^{11}$ (1996); JUNG et al. ${ }^{7}$ (1998) e GANSS et al. ${ }^{5}$ (1998).
A confrontação entre sistemas adesivos que usam condicionamento ácido total com os sistemas autocondicionantes não apresenta diferenças de comportamento, ou seja, ambos promovem condicionamento e limpeza da dentina para que não ocorra interferências na polimerização das resinas e para que efetivamente ocorra a reação de adesividade.

\section{CONCLUSÕES}

1. O sistema adesivo tradicional - Scotchbond Multi-Purpose - e o sistema autocondicionante Clearfil Liner Bond 2 - apresentam resultados semelhantes não significantes ao nível de $1 \%$ na polimerização da resina composta $Z 100$.

2. O condicionamento ácido usado isoladamente ou em conjunto com o sistema adesivo é suficiente para remover eventuais resíduos de eugenol da superfície dentinária.

SOUZA, A. R.; MELLO, F. B.; TURBINO, M. L.; YOUSSEF, M. N. Influence of eugenol on the microhardness of composite resin using current bonding systems. Pesqui Odontol Bras, v. 14, n. 3, p. 237-242, jul./set. 2000.

The zinc oxide-eugenol cement is still widely used as a temporary restorative material. Its use is known, however, to disturb the curing process of composite resins used in the final restoration. Nevertheless, with the development of dentin bonding systems, total etch is used to remove or treat the smear layer before the construction of the composite resin restoration. The purpose of this study was to evaluate if the zinc oxide-eugenol cement influenced the microhardness of composite resin (Z100) restorations used in association with either one of two bonding systems (Scotchbond Multi-Purpose Plus ${ }^{\mathbb{B}}$ and Clearfil Liner Bond $2^{\mathbb{B}}$ ). Forty molars were divided into four groups. For each bonding material there was a control group that did not receive cement and a group that received a temporary zinc oxide-eugenol restoration that was removed after seven days. The specimens were stored in a dry heat sterilizer at $37^{\circ} \mathrm{C}$, for seven days before the sectioning procedure. Microhardness was measured $0.3 \mathrm{~mm}$ far from the tooth-restoration interface by means of a SHIMADZU HMV 2000 apparatus, with a Knoop hardness tip of $50 \mathrm{~g}$, for 45 seconds. Statistical analysis of the results was performed using ANOVA $(\alpha=1 \%)$ and revealed no statistically significant differences in the microhardness of the composite resin, among the studied groups.

UNITERMS: Dentin-bonding agents; Zinc oxide-eugenol cement; Composite resins.

\section{REFERÊNCIAS BIBLIOGRÁFICAS}

1. BUONOCORE, M. G. A simple method of increasing the adhesion of acrylic filling materials to enamel surfaces. $\mathbf{J}$ Dent Res, v. 34, n. 6, p. 849-853, 1955.

2. CHAN, A. R.; TITLEY, K. C.; CHERNECKY, R. et al. A short and long-term shear bond strength study using acids of varying dilutions on bovine dentine. J Dent, v. 25, n. 2, p. 145-152, Mar. 1997.

3. CHIGIRA, H.; YUKITANI, W.; HASEGAWA, T. et al. Self-etching dentin primers containing phenyl-P. J Dent Res, v. 73, n. 5, p. 1088-1095, May 1994.

4. EliAdeS, G.; PALAGHIAS, G. H.; VOUGIOUKLAKIS, G. Effect of acid conditioners on dentin morfology, molecular composition and collagen conformation in situ. Dent Mater, v. 13, n. 1, p. 24-33, Jan. 1997.
5. GANSS, C.; JUNG, M. Effect of eugenol-containing temporary cements on bond strength of composite to dentin. Oper Dent, v. 23, n. 2, p. 55-62, Mar./Apr. 1998.

6. HARRINGTON, E.; WILSON, H. J.; SHORTAL, A. C. Light-activated restorative material: a method of determining effective radiation times. J Oral Rehabil, v. 23, n. 3, p. 210-218, 1996.

7. JUNG, M.; GANSS, C.; SENGER, S. Effect of eugenol-containing temporary cements on strength of composite to enamel. Oper Dent, v. 23, n. 2, p. 63-68, Mar./Apr. 1998.

8. LÓSSIO, J. J. A. Seleção e uso clínico de materiais das restaurações. São Paulo: Santos, 1987. 32 p.

9. MATSON, E. Atlas de Dentística Restauradora. 3. ed. São Paulo: Pancast Editorial, 1992. 84 p.

10. MATSON, E.; BOCANGEL, J. S.; PALMA, R. G. et al. 
SOUZA, A. R.; MELLO, F. B.; TURBINO, M. L.; YOUSSEF, M. N. Influência do eugenol na microdureza da resina composta utilizando sistemas adesivos atuais. Pesqui Odontol Bras, v. 14, n. 3, p. 237-242, jul./set. 2000.

Infiltração marginal de dois sistemas de adesão à dentina: influência do eugenol. In: Reunião Anual da Sociedade Brasileira de Pesquisas Odontológicas, 13 Águas de São Pedro, 01-04 set. 1996. Anais. São Paulo, SBPqO, 1996, p. 141.

11. MATSON, E.; TURBINO, M. L.; DEMARCO, F. F. et al. Influência do eugenol na adesão à dentina de dois sistemas adesivos. In: Reunião Anual da Sociedade Brasileira de Pesquisas Odontológicas, 13. Águas de São Pedro, 01-04 set. 1996. Anais. São Paulo, SBPqO, 1996. p. 141.

12. NAKABAYASHI, N.; KOJIMA, K.; MASUHARA, E. Adhesive bonding with 4-META. Oper Dent, v. 17, n. 5, p. 125-130, 1992.

13. NAKABAYASHI, N.; KOJIMA, K.; MASUHARA, E. The promotion of adhesion by the infiltration of monomers into tooth substrates. J Biomed Mater Res, v. 16, n. 3, p. 265-273, 1982.

14. NAKABAYASHI, N.; WATANABE, I.; GENDUSA, N. J. Dentin adhesion of "modificated" 4-META-MMA-TBB resin function of HEMA. Dent Mater, v. 8, n. 4, p. 259-264, 1992.

15. PAIVA, J. G. I.; ANTONIAZZI, J. H. Endodontia: bases para a prática clinica, 2. ed. São Paulo : Artes Médicas, 1993, p. 397.
16. PRATI, C; CHERSONI, S.; MONGIORGI, R.; PASHLEY, D. H. Resin-infiltrated dentin layer formation of new bonding systems. Oper Dent, v. 23, n. 4, p. 185-194, July/Aug. 1998.

17. REALITY. Dental adhesives. 4. A Clearfil Liner Bond., v. 12 , n. 1 , p. 142-143, Jan. $1998^{a}$.

18. STRANG, R.; WHITTERS, C. J.; BROWN, D. et al. Dental materials: 1996 literature review. J Dent, v. 26, n. 3, p. 191-207, Mar. 1998.

19. TAY, F. R.; GWINNET, J. A.; WEY, S. H. Y. Relation between water content in acetone/alcohol based primer and interfacial ultrastructure. J Dent, v. 26, n. 2, p. 147-156, Mar. 1998.

20. TURBINO, M. L. Contribuição ao estudo da microdureza Knoop de resinas compostas na região próxima à área de união à dentina. São Paulo, 1997. 84 p. Tese (Doutorado). Faculdade de Odontologia, Universidade de São Paulo.

21. WATANABE, I.; NAKABAYASHI, N.; PASHLEY, D. H. Bonding to ground dentin by a phenyl-P self-etching primer. J Dent Res, v. 73, n. 6, p. 1212-1220, Jun. 1994.

22. YOUSSEF, M. N. Estudo comparativo de quatro filosofias adesivas quanto à penetração na dentina. Rev Assoc Paul Cir Dent, v. 52, n. 3, p. 236-239, maio/jun. 1998. 